\title{
On-line preparation of peroxymonocarbonate and its application for the study of energy transfer chemiluminescence to lanthanide inorganic coordinate complexes
}

\author{
Meilin Liu, Xianglei Cheng, Lixia Zhao and Jin-Ming Lin* \\ State Key Laboratory of Environmental Chemistry and Ecotoxicology, Research Centre for Eco-Environmental Sciences, Chinese \\ Academy of Sciences, PO Box 2871, 100085 Beijing, China
}

Received 5 October 2005; revised 15 December 2005; accepted 21 December 2005

\begin{abstract}
It has been shown that peroxymonocarbonate ion $\left(\mathrm{HCO}_{4}^{-}\right)$is a potent oxidant. In this study, a flow-injection system was developed in order to prepare on-line $\mathrm{HCO}_{4}^{-}$ion and the optimum conditions for the on-line preparation of $\mathrm{HCO}_{4}{ }^{-}$were studied in detail. We used $99 \%{ }^{13} \mathrm{C}$-enriched $\mathrm{NaHCO}_{3}$ to examine peroxymonocarbonate by ${ }^{13} \mathrm{C}-\mathrm{NMR}$ at $25^{\circ} \mathrm{C}$. An ultra-weak chemiluminescence (CL) was observed after mixing $\mathrm{H}_{2} \mathrm{O}_{2}$ and sodium bicarbonate in an organic co-solvent that can accelerate the formation of $\mathrm{HCO}_{4}^{-}$ion. When lanthanide inorganic coordinate complex, Eu(II)-EDTA, was added into this $\mathrm{HCO}_{4}^{-}$system, the CL intensity was significantly enhanced. The CL mechanism was investigated by various methods. The experimental results indicate that peroxymonocarbonate oxidizes $\mathrm{Eu}(\mathrm{II})$ to $\mathrm{Eu}(\mathrm{III})$ and produces singlet oxygen; meanwhile, the energy originating from dimers of singlet oxygen is accepted by the Eu(III)-EDTA ${ }^{-}$complex. The excited Eu(III) ions undergo radiative deactivation and emit CL. Copyright (C) 2006 John Wiley \& Sons, Ltd.
\end{abstract}

KEYWORDS: peroxymonocarbonate; on-line; chemiluminescence; energy transfer; coordinate complexes

\section{INTRODUCTION}

Chemiluminescence $(\mathrm{CL})$ is a powerful analytical technique that has excellent sensitivity and wide linear dynamic range and requires relatively simple and inexpensive instrumentation $(1,2)$. It can be advantageously coupled with flow injection (FI) in order to capitalize on the advantages of FI, viz. simple, rapid, reproducible mixing of sample and reagents, and suitability for automatic and continuous analysis. The CL systems are few compared with fluorescence systems and UV-visible absorbance systems. Only about 20 kinds of reagents can be used as CL oxidants, which limits the applications of CL systems, whereas fluorescence systems and UVvisible absorbance systems involve many oxidants.

\footnotetext{
*Correspondence to: J.-M. Lin, State Key Laboratory of Environmental Chemistry and Ecotoxicology, Research Centre for EcoEnvironmental Sciences, Chinese Academy of Sciences, PO Box 2871, 100085 Beijing, China.

E-mail: jmlin@mail.rcees.ac.cn

Contract/grant sponsor: National Science Fund for Distinguished Young Scholars of China; Contract/grant number: 20125514.

Contract/grant sponsor: Natural Science Foundation of China; Contract/grant number: 20437020; Contract/grant number: 50273046. Contract/grant sponsor: Chinese Academy of Sciences; Contract/grant number: KZCX3-SW-432.
}

In CL systems, common oxidants include luminol, lucigenin, peroxalate, potassium permanganate, hydrogen peroxide, $\mathrm{Ce}(\mathrm{IV})$ and $\mathrm{K}_{3}\left[\mathrm{Fe}(\mathrm{CN})_{6}\right]$. They are widely employed in CL analytical applications. Recently, the formation of a bicarbonate active species, peroxymonocarbonate $\left(\mathrm{HCO}_{4}^{-}\right)$, was reported (3). It was shown that $\mathrm{HCO}_{4}^{-}$is a potent oxidant in aqueous solution (electrode potential $1.8 \pm 0.1 \mathrm{~V}$ vs. NHE). The reaction of $\mathrm{H}_{2} \mathrm{O}_{2}$ and bicarbonate to form $\mathrm{HCO}_{4}^{-}$ occurs in aqueous solution and alcohol/water mixtures:

$$
\mathrm{HCO}_{3}^{-}+\mathrm{H}_{2} \mathrm{O}_{2} \rightleftharpoons \mathrm{HCO}_{4}^{-}+\mathrm{H}_{2} \mathrm{O}
$$

The acceleration of oxidation reactions upon formation of $\mathrm{HCO}_{4}^{-}$from $\mathrm{H}_{2} \mathrm{O}_{2}$ and $\mathrm{HCO}_{3}^{-}$arises from a kinetic advantage for the oxidation by $\mathrm{HCO}_{4}^{-}$. The activation of $\mathrm{H}_{2} \mathrm{O}_{2}$ for synthetic transformations proceeding via heterolytic oxidation is typically achieved through the formation of peroxyacids, which are generally several orders of magnitude more reactive toward nucleophilic substrates than $\mathrm{H}_{2} \mathrm{O}_{2}$ itself (4). This data suggested to us that the active species $\mathrm{HCO}_{4}^{-}$has similar characteristics to peroxomonosulphate $\left(\mathrm{HSO}_{5}^{-}\right)$, which has been used as $\mathrm{CL}$ analytical reagent (5). The oxidation potential of $\mathrm{HSO}_{5}{ }^{-}$is $1.82 \mathrm{~V} \mathrm{(6)}$, which is near to the electrode potential of $\mathrm{HCO}_{4}^{-} / \mathrm{HCO}_{3}^{-}$. 
Peroxymonocarbonate ion $\left(\mathrm{HCO}_{4}^{-}\right)$is capable of oxidizing a variety of substances, such as methionine (7), alkenes $(8-10)$ and sulphide $(3,11)$. Moreover, peroxymonocarbonate is formed in a few minutes at $\mathrm{pH}$ 7-9 with no acid catalyst added. The reaction of equation 1 was studied by Griffith and co-workers by NMR (12), and they also noted that the equilibration of $\mathrm{HCO}_{4}^{-}$is completed within several minutes in water. Drago and co-workers (13) reported comparable studies in mixed alcohol/water solvents in which the equilibration is completed in minutes. However, the oxidant is unstable and hydrolyses rapidly, forming $\mathrm{HCO}_{3}{ }^{-}$and $\mathrm{H}_{2} \mathrm{O}_{2}$, and it is relatively difficult to store the $\mathrm{HCO}_{4}^{-}$ions. Thus, it was considered that on-line preparation of $\mathrm{HCO}_{4}{ }^{-}$was likely to be the preferable method in most applications. Moreover, the $\mathrm{CL}$ system with on-line $\mathrm{HCO}_{4}^{-}$as oxidant has not yet been reported, to the best of our knowledge. In this study, FI technique was used to introduce a continuous flowing stream into the channel. In view of these data, a FI method for the on-line preparation of peroxymonocarbonate ion $\left(\mathrm{HCO}_{4}^{-}\right)$was developed and its application to an energy transfer CL system was studied. It was found that an ultra-weak CL was observed after mixing $\mathrm{H}_{2} \mathrm{O}_{2}$ and sodium bicarbonate in an organic co-solvent that can accelerate the formation of $\mathrm{HCO}_{4}{ }^{-}$ ion. When lanthanide inorganic coordinate complex, $\mathrm{Eu}$ (II)-EDTA, was added into this $\mathrm{HCO}_{4}^{-}$system, the CL intensity was significantly enhanced. The CL mechanism was investigated in detail by electron spin resonance (ESR) spin-trapping technique, mass spectral (MS) technique, fluorescence spectra, UV-visible absorbance and a CL method.

\section{EXPERIMENTAL}

\section{Apparatus}

A FI system with CL detection used in this work is shown in Fig. 1. A peristaltic pump (Baoding Longer Precision Pump Co. Ltd, China) was used to deliver all flow lines at a flow rate of $1.1 \mathrm{~mL} / \mathrm{min}$. PTFE tubing ( $0.8 \mathrm{~mm}$ i.d.) was used as connection material in the flow system. The flow cell was a flat spiral-coiled colourless glass tube $(1.0 \mathrm{~mm}$ i.d.; total diameter of the flow cell, $3 \mathrm{~cm}$, without gaps between loops) and placed close to the window of the photomultiplier tube (PMT). The $\mathrm{HCO}_{4}^{-}$solution was prepared on-line by mixing $\mathrm{H}_{2} \mathrm{O}_{2}$ and bicarbonate through a three-way piece. A $35 \mathrm{~cm}$ mixing coil was used for efficient mixing of the $\mathrm{H}_{2} \mathrm{O}_{2}$ and bicarbonate. A $\mathrm{Eu}(\mathrm{II})$ solution $(150 \mu \mathrm{L})$ was injected into the carrier stream (EDTA) through the six-way valve, and then merged just prior to reaching the flow cell with the stream of $\mathrm{HCO}_{4}^{-}$solution. The $\mathrm{CL}$ signal produced in the flow cell was collected by a CR-105 PMT (Hamamatsu, Japan, operated at $-800 \mathrm{~V}$ ).

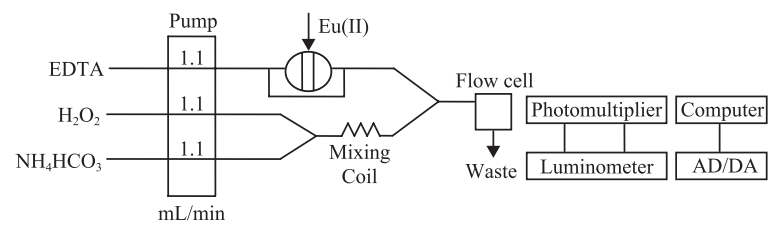

Figure 1. Schematic diagram of flow-injection CL detection system for the on-line preparation of $\mathrm{HCO}_{4}^{-}$and the investigation of energy transfer CL.

Batch chemiluminescence experiments were carried in a BPCL luminescence analyser (Institute of Biophysics, Chinese Academy of Sciences, Beijing, China). UVvisible absorption spectra, ESR spin trapping spectra and mass spectra were measured on the UV-2401 spectrophotometer (Shimadzu, Japan), X-band ESP300E spectrometer (Bruker, Germany) and a Platform II mass spectrometer (LSMS-2010, Shimadzu, Japan), respectively.

\section{Reagents and instrumentation}

The $\mathrm{EuCl}_{3}$ solution was prepared by dissolving $\mathrm{Eu}_{2} \mathrm{O}_{3}$ (Alfa Aesar, Belgium) in $\mathrm{HCl}$. Reduction of $\mathrm{EuCl}_{3}$ to $\mathrm{EuCl}_{2}$ was performed using McCoy's method (14). The degree of reduction was determined by the iodometric method directly prior to measurement. A stock standard solution $(0.1 \mathrm{~mol} / \mathrm{L})$ of ethylenediaminetetraacetate disodium salt (EDTA) was prepared by dissolving the compounds in distilled water. Working solutions of $\mathrm{H}_{2} \mathrm{O}_{2}$ were prepared fresh daily in ethanol (ethanol:water 1.76:1 v/v) from $\mathrm{H}_{2} \mathrm{O}_{2}(30 \%$; GR, Alfa Aesar, USA). Ammonium bicarbonate (AR) and ethanol (AR) were used as received.

All the reagents used in these experiments were of analytical grade without further purification. Water was purified using a compact ultrapure water system (18.3 M $\Omega / \mathrm{cm}$; Barnstead, Iowa, USA).

\section{Procedure}

The on-line preparation of $\mathrm{HCO}_{4}^{-}$in the presence of bicarbonate and various substrates was studied using the FI technique. The CL signal was recorded by injecting $150 \mu \mathrm{L} \mathrm{Eu(II)}$ into an EDTA stream and mixing with $\mathrm{HCO}_{4}^{-}$, and the $\mathrm{CL}$ peak height was then measured.

\section{RESULTS AND DISCUSSION}

\section{On-line preparation for $\mathrm{HCO}_{4}^{-}$by $\mathrm{Fl}$ technique}

Taking into account the relative difficulty of storing the unstable $\mathrm{HCO}_{4}^{-}$, on-line preparation of $\mathrm{HCO}_{4}^{-}$ 
is likely to be the preferable method. FI analysis is a fast and continuous form of analysis. Based on instant discrete sampling by injecting into a carrier stream, the system allows continuous flow analysis to be performed in a rapid and simplified way. As the continuous flowing stream is characterized by a turbulent rather than a laminar flow, the discrete instant sampling creates geometrically well-defined segments of sample solution within the flowing stream. FI analysis introduces a continuous flowing stream into the channel, which makes the on-line mixing effective. At the same time, by using the peristaltic pump, it is easy to control the flow rate for the appropriate on-line formation time.

The $\mathrm{HCO}_{4}^{-}$solution was prepared on-line by the mixing $\mathrm{H}_{2} \mathrm{O}_{2}$ and bicarbonate through a three-way piece. The flow system used in this work was shown in Fig. 1. It consists of a peristaltic pump with two lines. The flow lines $\mathrm{H}_{2} \mathrm{O}_{2}$ in 1.76:1 ethanol:water solution and bicarbonate were used to produce the on-line $\mathrm{HCO}_{4}{ }^{-}$ions. The mixing time interval and the flow rates of $\mathrm{H}_{2} \mathrm{O}_{2}$ and bicarbonate play key roles in the on-line preparation of $\mathrm{HCO}_{4}{ }^{-}$solution. The $\mathrm{CL}$ emission intensity was used to quantify $\mathrm{HCO}_{4}^{-}$ions. A time that was too long or too short did not lead to the formation of enough $\mathrm{HCO}_{4}{ }^{-}$ ions to induce $\mathrm{CL}$ emission. In addition, the life of the active carbon oxygen intermediate is a dominant factor in deciding the CL intensity in flow injection CL emission, because transient light emission is monitored. It was reported that the half-life for the formation of $\mathrm{HCO}_{4}^{-}$ions in ethanol:water $(1.76: 1 \mathrm{v} / \mathrm{v})$ medium is ca. $300 \mathrm{~s} \mathrm{(3),} \mathrm{which} \mathrm{means} \mathrm{that} \mathrm{the} \mathrm{HCO}_{4}{ }^{-}$ion is relatively stable in organic solvent. Since the lifetime of the $\mathrm{HCO}_{4}^{-}$ is very short, the point of mixing was designed to be inside the CL cell.

Meanwhile, the concentrations of mixing reagent solutions $\left(\mathrm{H}_{2} \mathrm{O}_{2}\right.$ and bicarbonate $)$ could directly influence the on-line preparation of $\mathrm{HCO}_{4}^{-}$ions. The concentration of $\mathrm{H}_{2} \mathrm{O}_{2}$ in a range of $0-4 \mathrm{~mol} / \mathrm{L}$ in ethanol:water (1.76:1 v/v) was examined. High $\mathrm{H}_{2} \mathrm{O}_{2}$ concentrations can give rise to gaps in the flow line. Very low $\mathrm{H}_{2} \mathrm{O}_{2}$ concentrations can not produce enough $\mathrm{HCO}_{4}^{-}$ions. After a series of experiments, $2 \mathrm{~mol} / \mathrm{L} \mathrm{H}_{2} \mathrm{O}_{2}$ was selected as the optimum. Due to the lower solubility in the mixed solvents, ammonium bicarbonate was used rather than group 1 salts, and the optimum concentration of ammonium bicarbonate for on-line $\mathrm{HCO}_{4}{ }^{-}$preparation was $0.05 \mathrm{~mol} / \mathrm{L}$. Furthermore, experiments with different mixing coil lengths and the effect of flow rates showed that when a $35 \mathrm{~cm}$ mixing coil and $1.1 \mathrm{~mL} / \mathrm{min}$ flow rate were used, the maximum $\mathrm{HCO}_{4}^{-}$was obtained. We used 99\% ${ }^{13} \mathrm{C}$-enriched $\mathrm{NaHCO}_{3}$ to examine bicarbonateperoxide in alcohol/water solvents by ${ }^{13} \mathrm{C}-\mathrm{NMR}$ at $25^{\circ} \mathrm{C}$. Concentrations of $\mathrm{H}_{2} \mathrm{O}_{2}$ in the range $0.2-4.0 \mathrm{~mol} / \mathrm{L}$ were employed, and $\left[\mathrm{H}^{13} \mathrm{CO}_{3}^{-}\right]=0.10 \mathrm{~mol} / \mathrm{L}$ was used for all studies.

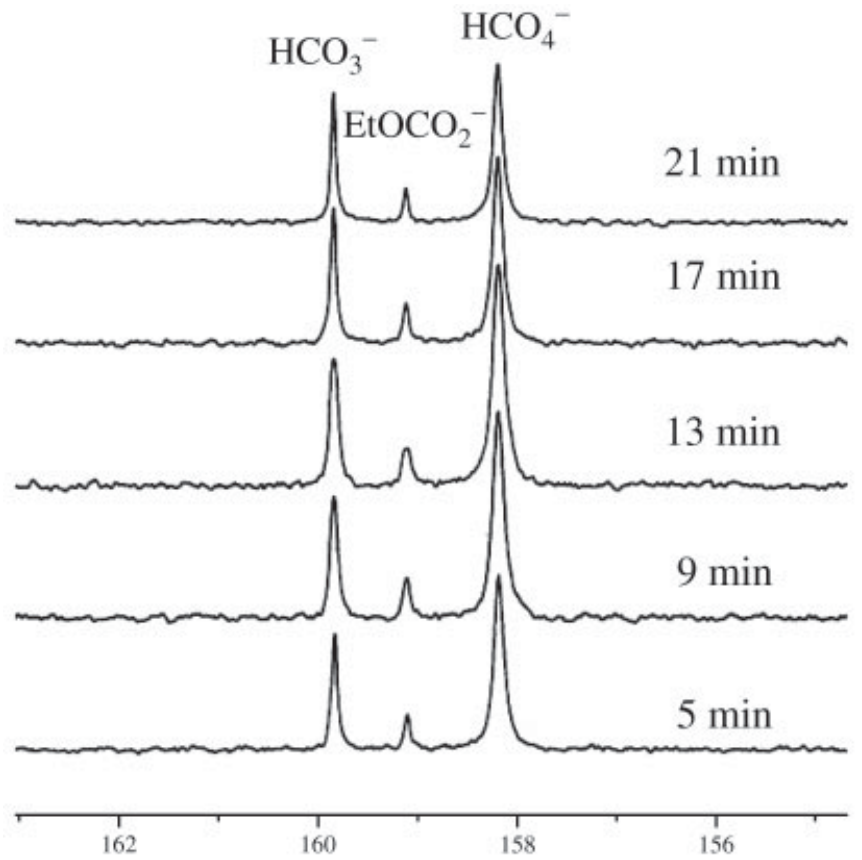

Figure 2. ${ }^{13} \mathrm{C}-\mathrm{NMR}$ spectra for a solution at $25^{\circ} \mathrm{C}$ of $\mathrm{NaH}^{13} \mathrm{CO}_{3}(0.05 \mathrm{~mol} / \mathrm{L})$ in 1.76:1 (v/v ethanol:water) with $\left[\mathrm{H}_{2} \mathrm{O}_{2}\right]=2.0 \mathrm{~mol} / \mathrm{L}$. Times shown are for the completion of acquisition from the time of mixing.

\section{Spectroscopic evidence for $\mathrm{HCO}_{4}^{-}$ions}

The peroxymonocarbonate ion has been isolated as various salts and characterized by vibrational spectroscopy (2) and X-ray crystallography (e.g. $\mathrm{KHCO}_{4} \cdot \mathrm{H}_{2} \mathrm{O}_{2}$ ) (3). Peroxymonocarbonate is a true peroxide with the structure $\mathrm{HOOCO}_{2}^{-}$. The solution properties of the ion have also been studied by NMR (8).

The ${ }^{13} \mathrm{C}-\mathrm{NMR}$ spectroscopic results strongly support the on-line formation of $\mathrm{HCO}_{4}^{-}$in the flow system (Fig. 2). Concentrations of $\mathrm{H}_{2} \mathrm{O}_{2}$ of ca. $2.0 \mathrm{~mol} / \mathrm{L}$ were employed, and $\left[\mathrm{H}^{13} \mathrm{CO}_{3}^{-}\right]=0.10 \mathrm{~mol} / \mathrm{L}$ for all studies. Besides the peak for bicarbonate at $163.6 \mathrm{ppm}$, a single additional peak at $161.7 \mathrm{ppm}$ assigned as $\mathrm{HCO}_{4}^{-}$ was observed (chemical shifts relative to TMS). We carried out a variable time dependence of the peak in ethanol:water. It was concluded that the unstable peroxymonocarbonate ions can exist for $20 \mathrm{~min}$. The ${ }^{13} \mathrm{C}$-NMR spectroscopic results strongly support the online formation of $\mathrm{HCO}_{4}^{-}$in the flow system. Thus, online preparation of $\mathrm{HCO}_{4}^{-}$ions offers the reliable intermediate for further investigation.

\section{Kinetics of the $\mathrm{CL}$ reaction}

As one of the rare earth elements, europium(II) ion complexes with various ligands have received much attention, owing to their unique luminescence properties, such as long luminescence decay time and narrow emission bands (15-17). Therefore, the Eu(II)-EDTA 

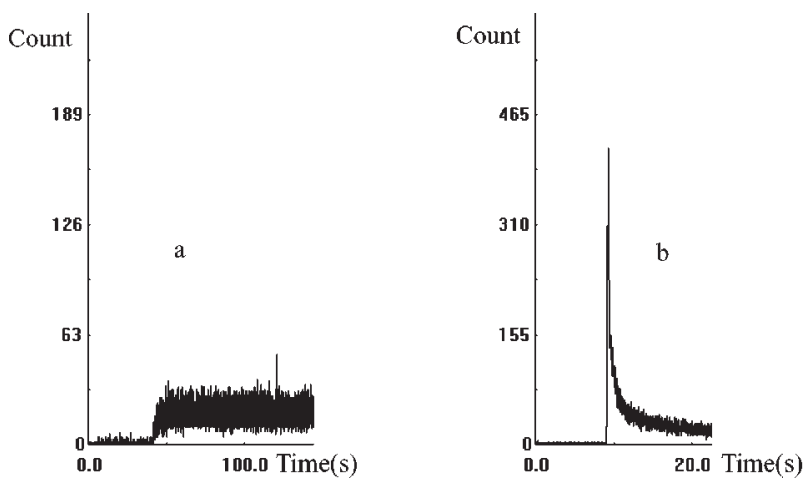

Figure 3. Chemiluminescent reaction kinetics. (a) $\mathrm{HCO}_{4}^{-}$system; (b) $\mathrm{HCO}_{4}^{-}-\mathrm{Eu}(\mathrm{II})-\mathrm{EDTA}$ system. Conditions: $2 \mathrm{~mol} / \mathrm{L}$ $\mathrm{H}_{2} \mathrm{O}_{2}$ (ethanol:water $\left.=1.76: 1\right), 0.05 \mathrm{~mol} / \mathrm{L} \mathrm{HCO}_{3}{ }^{-}, 0.01 \mathrm{~mol} / \mathrm{L}$ $\mathrm{Eu}(\mathrm{II}), 0.03 \mathrm{~mol} / \mathrm{L}$ EDTA.

complex was employed to investigate the energy transfer mechanism for $\mathrm{HCO}_{4}^{-}$ions. In a preliminary experiment, the effect of the order of mixing of the reagent solutions on the $\mathrm{CL}$ signal was studied by use of the batch method. From Fig. 3a and b, it is apparent that when $100 \mu \mathrm{L} 2 \mathrm{~mol} / \mathrm{L} \quad \mathrm{H}_{2} \mathrm{O}_{2}$ solution was injected into $100 \mu \mathrm{L} 0.05 \mathrm{~mol} / \mathrm{L} \mathrm{HCO}_{3}^{-}$, the $\mathrm{CL}$ emission was weak. When $100 \mu \mathrm{L} 0.01 \mathrm{~mol} / \mathrm{L}$ Eu(II)-EDTA (metal:ligand $=1: 3$ ) solution was injected into $100 \mu \mathrm{L}$ $2 \mathrm{~mol} / \mathrm{L}^{2} \mathrm{H}_{2} \mathrm{O}_{2}-0.05 \mathrm{~mol} / \mathrm{L}^{\mathrm{HCO}_{3}}{ }^{-}$in ethanol:water $(1.76: 1 \mathrm{v} / \mathrm{v})$, the $\mathrm{CL}$ intensity was greatly enhanced. The effects of $\mathrm{Eu}(\mathrm{III})$ and $\mathrm{Zn}^{2+}$ on the CL system were investigated. The experiments showed that these two ions have no effect on the CL signal.

\section{Study of mechanism for the CL reaction}

UV-Visible absorption spectra for Eu(II) ions before and after the reaction and the $\mathrm{CL}$ spectrum for the $\mathrm{CL}$ reaction. The absorption spectrum of $\mathrm{Eu}(\mathrm{II})$ ions in water reveals two bands with maxima at $\lambda=248$ and $318 \mathrm{~nm}$ (Fig. 4a), ascribed to the electronic transitions $4 \mathrm{f}^{7}$ $\rightarrow 4 \mathrm{f}^{6} 5 \mathrm{~d}$ (18). In the concentration range $10^{-4}-10^{-2} \mathrm{~mol} / \mathrm{L}$, at $\lambda=248 \mathrm{~nm}$, the $\mathrm{Eu}^{2+}$ solutions satisfied the LambertBeer law. The other components of the system studied, $\mathrm{H}_{2} \mathrm{O}_{2}, \mathrm{HCO}_{3}{ }^{-}$and $\mathrm{HCO}_{4}^{-}$, did not give significant signals at $\lambda=248 \mathrm{~nm}$, and this was utilized for the $\mathrm{Eu}^{2+}$ study before and after the reaction. Two bands (248 and $318 \mathrm{~nm}$ ) disappeared from the absorption spectrum after the reaction (Fig. 4b). Moreover, this absorption spectrum did not superimpose on the Eu(III) absorption spectrum (Fig. 4c). However, the two shapes were very similar. Based on this, we concluded that Eu(II) was oxidized to $\mathrm{Eu}$ (III) after the $\mathrm{HCO}_{4}^{-}-\mathrm{Eu}(\mathrm{II})$-EDTA CL reaction. In the redox system of $\mathrm{Ru}^{2+} / \mathrm{Ru}^{3+}$ with $2,2^{\prime}$ bipyridine, the excited product was identified as a metal to ligand charge transfer triplet (19), which is similar to $\mathrm{Eu}^{2+} / \mathrm{Eu}^{3+}$. In addition, Elbanowsli (20) found that the $\left[\mathrm{Eu}(\mathrm{II})-\mathrm{N}_{3}\right]^{2+}$ complex can easily accept energy from singlet oxygen dimers. We therefore deduced that it is possible that singlet oxygen originates from the $\mathrm{CL}$ reaction of the $\mathrm{HCO}_{4}^{-}-\mathrm{Eu}(\mathrm{II})-\mathrm{EDTA}$ system, which induced the $\mathrm{CL}$ emission. We examined the presence of singlet oxygen using various methods, including CL, ESR spin-trapping and a mass spectroscopic method.

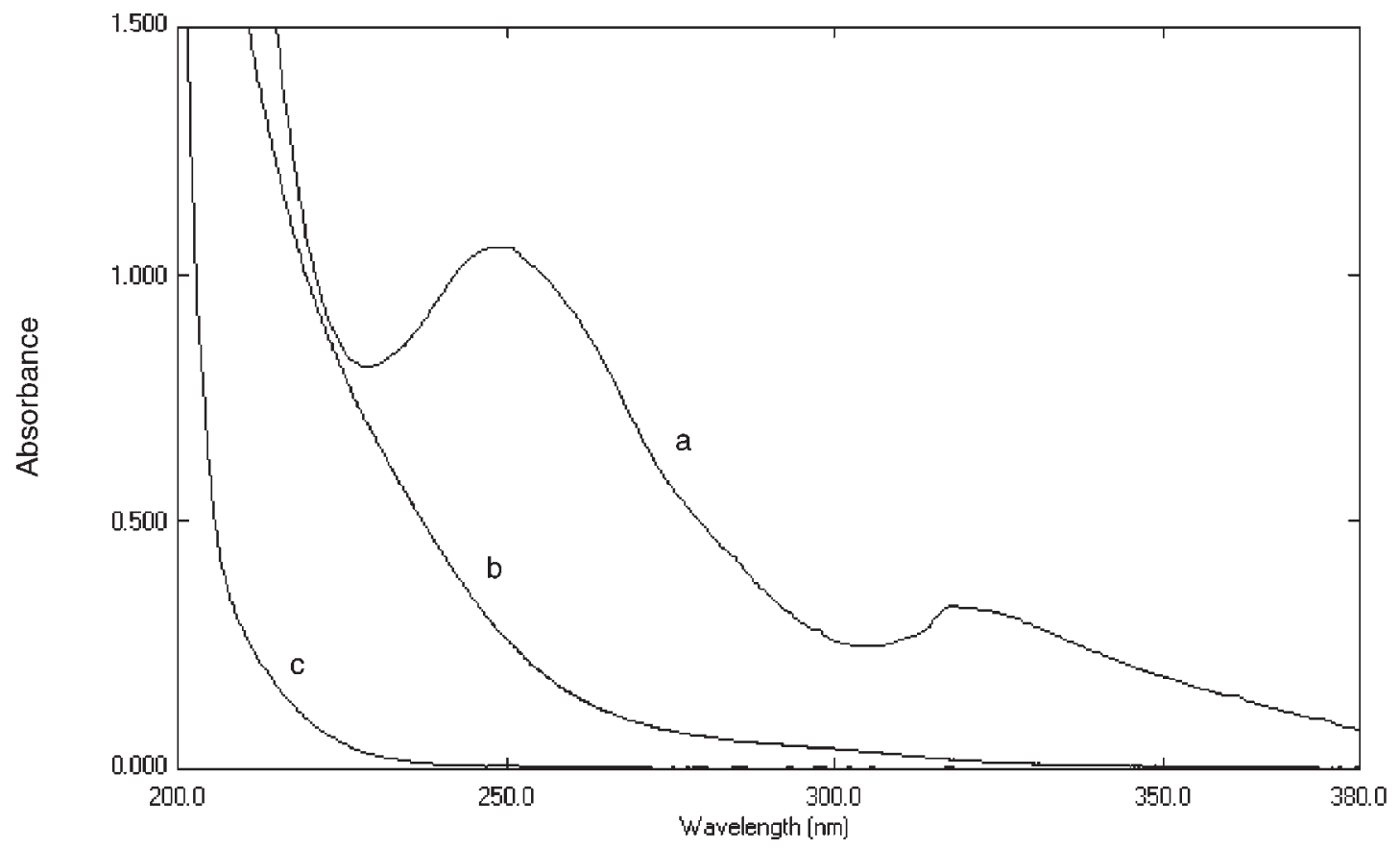

Figure 4. Absorption spectra of (a) $\mathrm{Eu}(\mathrm{II})$, (b) $\mathrm{Eu}(\mathrm{II})$ after reaction and (c) Eu(III); concentration of all reagents: $1 \times 10^{-3} \mathrm{~mol} / \mathrm{L}$. 
Preliminary examination of ${ }^{1} \mathrm{O}_{2}$ participation in the $\mathrm{HCO}_{4}^{-}-\mathrm{Eu}(\mathrm{II})-\mathrm{EDTA} \mathrm{CL}$ emission. The $p$ methoxyphenyl Cypridina luciferin analogue (MCLA) has been used as a CL probe for the determination of $\mathrm{O}_{2}{ }^{--}$and ${ }^{1} \mathrm{O}_{2}$ (21). In the $\mathrm{CL}$ reaction, MCLA enhanced greatly the CL intensity. Simultaneously, the quenching effect on the $\mathrm{CL}$ by ${ }^{1} \mathrm{O}_{2}$ scavenger sodium azide (22) was also confirmed (about 13-fold). These facts preliminarily confirm the participation of ${ }^{1} \mathrm{O}_{2}$.

ESR studies of ${ }^{1} \mathrm{O}_{2}$ participation in the $\mathrm{HCO}_{4}^{-}-\mathrm{Eu}(\mathrm{II})-$ EDTA CL system. 2,2,6,6-tetramethyl-4-piperidone (4oxo-TEMP), a specific target for ${ }^{1} \mathrm{O}_{2}$, was used as the spin-trap. The reaction of ${ }^{1} \mathrm{O}_{2}$ with TEMP results in the formation of 2,2,6,6-tetramethylpiperidine- $\mathrm{N}$-oxide (TEMPO) $(23,24)$, the product being a stable nitroxide radical with a characteristic spectrum. The reagents were dissolved in appropriate amounts in alcohol. Alcohol was chosen as the co-solvent because TEMP is soluble in alcohols, the lifetime of ${ }^{1} \mathrm{O}_{2}$ was increased six times in comparison to $\mathrm{H}_{2} \mathrm{O}$, and an interaction of $\cdot \mathrm{OH}$ with TEMPO is suppressed. The electron spin resonance (ESR) data supports the formation of ${ }^{1} \mathrm{O}_{2}$ during the $\mathrm{HCO}_{4}{ }^{-}-\mathrm{Eu}(\mathrm{II})-\mathrm{EDTA}$ CL process, and Fig. 5 shows the ESR spectrum of the reaction system.

Chemical trapping of ${ }^{1} \mathrm{O}_{2}$ and mass spectrometry analysis. The ${ }^{1} \mathrm{O}_{2}$ in the reaction of $\mathrm{HCO}_{4}^{-}-\mathrm{Eu}(\mathrm{II})-$ EDTA system was chemically detected by the rapid and specific reaction of 9,10-diphenylanthracene (DPA)

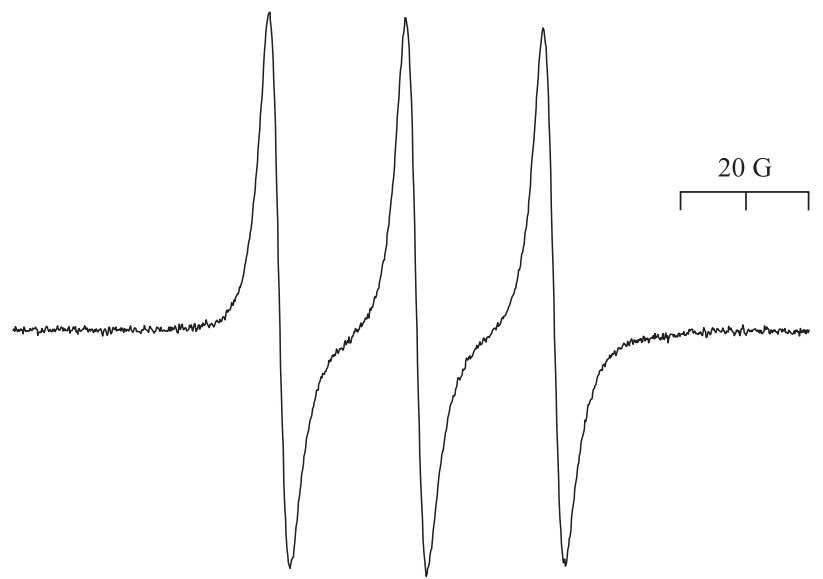

Figure 5. ESR spectrum of nitroxide radicals generated by reaction of the TEMP probe in the $\mathrm{HCO}_{4}^{-}-\mathrm{Eu}(\mathrm{II})-\mathrm{EDTA}$ system. Conditions: receiver gain, $8.00 \mathrm{e}+04$; mod amplitude, $1 \mathrm{G}$; sweep width, $100.00 \mathrm{G}$; microwave power, $3.17 \mathrm{e}+00 \mathrm{~mW}$.

and ${ }^{1} \mathrm{O}_{2}$, forming a stable endoperoxide $\left(\mathrm{DPAO}_{2}\right)$ $\left(k_{\mathrm{r}}=1.3 \times 10^{6} \mathrm{~mol} / \mathrm{L} / \mathrm{s}\right)$ (25). After the reaction, the solution was diluted 1:100. DPA and the endoperoxide $\left(\mathrm{DPAO}_{2}\right)$ was analysed by electrospray ionization tandem mass spectrometry (LSMS-2010, Shimadzu). The mass spectrum of DPA recorded in the positive mode exhibits a major $[\mathrm{M}]^{+}$ion at $\mathrm{m} / \mathrm{z}=330$, corresponding to the positively charged molecular ion. The spectrum of $\mathrm{DPAO}_{2}$ displays an intense $[\mathrm{M}+\mathrm{H}]^{+}$ion at $m / z=363$ (Fig. 6). The reaction of $\mathrm{HCO}_{4}^{-}$and $\mathrm{Eu}$ (II)

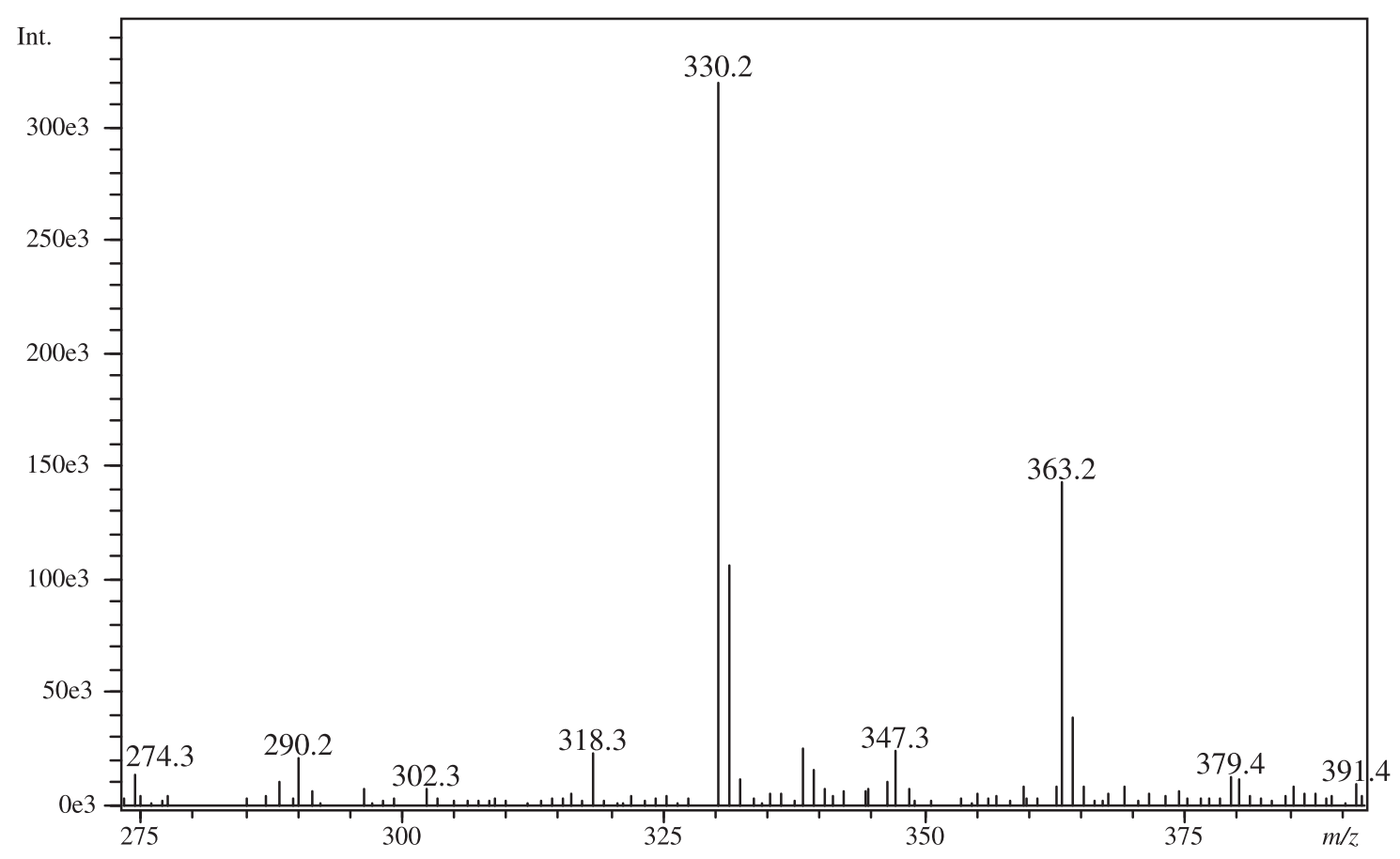

Figure 6. Mass spectra of DPA and $\mathrm{DPAO}_{2}$ by chemical trapping with the DPA $(60 \mathrm{mmol} / \mathrm{L})$. 


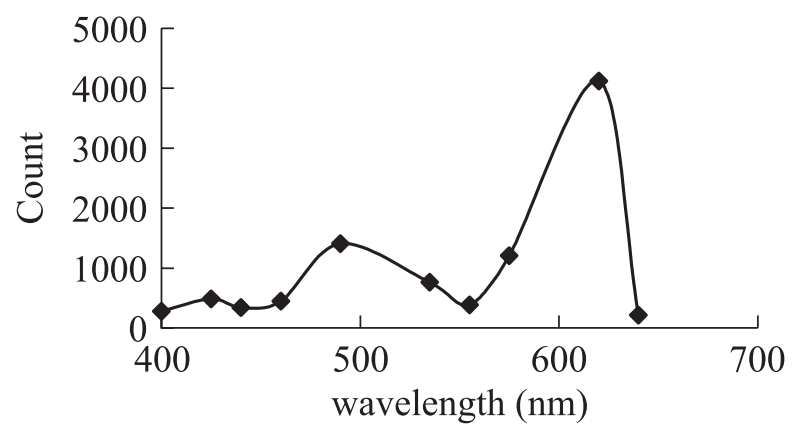

Figure 7. The $\mathrm{CL}$ spectra for the $\mathrm{HCO}_{4}^{-}-\mathrm{Eu}(\mathrm{II})-\mathrm{EDTA}$ system.

in the presence of $60 \mathrm{mmol} / \mathrm{L}$ DPA resulted in the formation of $\mathrm{DPAO}_{2}$. Detection of the anthracene endoperoxide $\left(\mathrm{DPAO}_{2}\right)$ provided another powerful proof of the participation of ${ }^{1} \mathrm{O}_{2}$ in the $\mathrm{HCO}_{4}^{-}-\mathrm{Eu}(\mathrm{II})_{-}$ EDTA CL system. For comparison purposes, we also successfully detected the ${ }^{1} \mathrm{O}_{2}$ derived from the $\mathrm{H}_{2} \mathrm{O}_{2}-$ molybdate (26) and $\mathrm{H}_{2} \mathrm{O}_{2}$-hypochlorite (27) systems by mass spectrometry. These novel observations identified the generation of ${ }^{1} \mathrm{O}_{2}$ in the reaction of $\mathrm{HCO}_{4}^{-}$with $\mathrm{Eu}$ (II)-EDTA, suggesting a potential ${ }^{1} \mathrm{O}_{2}$-dependent energy transfer CL mechanism.

The CL spectrum of this system determined with cut-off filters is shown in Fig. 7. There are two peaks in the range $400-640 \mathrm{~nm}$. The second peak $(615 \mathrm{~nm})$ is characteristic of $\mathrm{Eu}(\mathrm{III})$. It can be concluded that the $\mathrm{CL}$ emission arose from the $\mathrm{Eu}(\mathrm{III})$.

Many investigations have indicated that lanthanide ions, mainly $\mathrm{Eu}(\mathrm{II}), \mathrm{Eu}(\mathrm{III})$ and $\mathrm{Tb}(\mathrm{III})$, show strong luminescence, and have been used as luminescent probes and donors or acceptors. $\mathrm{HCO}_{4}^{-}$, as an active carbon oxygen intermediate, has high activity and readily oxidizes $\mathrm{Eu}(\mathrm{II})$ to $\mathrm{Eu}(\mathrm{III}): \mathrm{HCO}_{4}^{-}+\mathrm{Eu}(\mathrm{II}) \rightarrow \mathrm{CO}_{3}^{-}$ $+\mathrm{OH}+\mathrm{Eu}(\mathrm{III})$. We found that no CL was observed in the presence of $\mathrm{Eu}(\mathrm{III})$, whereas adding $\mathrm{Eu}(\mathrm{II})$ into the system produced a bright CL. This showed that the process of CL was initiated by addition of $\mathrm{Eu}$ (II) to a solution containing $\mathrm{HCO}_{4}^{-}$. The $\mathrm{HCO}_{4}^{-}-\mathrm{Eu}(\mathrm{II})$ system is also a source of $\cdot \mathrm{OH}$ radicals. In the $\mathrm{CL}$ system, the products of the simultaneous processes of $\mathrm{HCO}_{4}^{-}$ decomposition and radical recombination are molecules of ${ }^{1} \mathrm{O}_{2}$ :

$$
\begin{gathered}
\mathrm{H}_{2} \mathrm{O}_{2}+\mathrm{CO}_{3}^{-} \rightarrow \mathrm{HCO}_{3}^{-}+\mathrm{HO}_{2} \cdot(28) \\
\mathrm{HO}_{2} \cdot \rightarrow \mathrm{H}^{+}+\mathrm{O}_{2}^{-}(\mathrm{pK}=4.8)(29) \\
\mathrm{O}_{2}^{-}+\cdot \mathrm{OH} \rightarrow{ }^{1} \mathrm{O}_{2}+\mathrm{HO}^{-} \\
\mathrm{O}_{2}^{-}+\cdot \mathrm{OH}+\mathrm{H}^{+} \rightarrow{ }^{1} \mathrm{O}_{2}+\mathrm{H}_{2} \mathrm{O} \\
\mathrm{HO}_{2} \cdot+\mathrm{HO}_{2} \cdot \rightarrow{ }^{1} \mathrm{O}_{2}+\mathrm{H}_{2} \mathrm{O}_{2}
\end{gathered}
$$

A product of $\mathrm{Eu}(\mathrm{II})$ ion oxidation by peroxymonocarbonate is excited $\mathrm{Eu}$ (III) ions which, on returning to the ground state, emit light at $615 \mathrm{~nm}$ corresponding to the transition ${ }^{5} \mathrm{D}_{0}-{ }^{7} \mathrm{~F}_{2}$. The intensity of emission of the lanthanide ions depends on the stability of the complex formed with the ligand and the hydration number (30, 31 ). The presence of $\mathrm{Eu}(\mathrm{II})$ and EDTA results in a significant increase in CL emission. In the CL spectra, the dominant band is attributed to $\mathrm{Eu}(\mathrm{III})$, with the maximum at about $615 \mathrm{~nm}$ (32), which indicates that these ions are the only emitters in the system studied. On the basis of the results obtained, the following reaction mechanism can be proposed:

$$
\begin{array}{r}
\mathrm{O}_{2}\left({ }^{1} \Delta_{\mathrm{g}}\right)+\mathrm{O}_{2}\left({ }^{1} \Delta_{\mathrm{g}}\right) \rightarrow \mathrm{O}_{2}\left({ }^{1} \Sigma_{\mathrm{g}}^{+}\right)+\mathrm{O}_{2}\left({ }^{3} \Sigma_{\mathrm{g}}{ }^{-}\right) \\
K=1.3 \times 10^{3} \\
\mathrm{O}_{2}\left({ }^{1} \Sigma_{\mathrm{g}}^{+}\right)+\mathrm{O}_{2}\left({ }^{1} \Delta_{\mathrm{g}}\right)+[\mathrm{Eu}(\mathrm{III})(\mathrm{EDTA})]^{-} \rightarrow \\
2 \mathrm{O}_{2}\left({ }^{3} \Sigma_{\mathrm{g}}^{-}\right)+\left[\mathrm{Eu}(\mathrm{III})(\mathrm{EDTA})^{*}\right]^{-} \\
{\left[\mathrm{Eu}(\mathrm{III})(\text { EDTA })^{*}\right]^{-} \rightarrow[\mathrm{Eu}(\mathrm{III}) *(\text { EDTA })]^{-}} \\
{[\mathrm{Eu}(\mathrm{III}) *(\mathrm{EDTA})]^{-} \rightarrow[\mathrm{Eu}(\mathrm{III})(\text { EDTA })]^{-}+\mathrm{h} v}
\end{array}
$$

Besides the dominant band at $615 \mathrm{~nm}$, they include a low-intensity band with a maximum at about $500 \mathrm{~nm}$, which can be interpreted as arising from the emission of excited carbonyl groups $(33,34)$.

\section{CONCLUSION}

We have developed a method for on-line production of peroxymonocarbonate. A high electrode potential for the $\mathrm{HCO}_{4}^{-}-\mathrm{HCO}_{3}^{-}$couple $(1.8 \pm 0.1 \mathrm{~V}$ vs. NHE) can induce ultra-weak $\mathrm{CL}$ in the $\mathrm{HCO}_{4}^{-}-\mathrm{Eu}$ (II)/Eu(III) system. When EDTA is added into this system, the $\mathrm{CL}$ emission intensity was efficiently enhanced. The $\mathrm{HCO}_{4}{ }^{-}-\mathrm{Eu}(\mathrm{II}) / \mathrm{Eu}(\mathrm{III})-\mathrm{EDTA} \mathrm{CL}$ system was investigated in detail using MS, ESR spin-trapping techniques and a CL method and a mechanism for the process was proposed. The results indicate that peroxymonocarbonate oxidizes $\mathrm{Eu}(\mathrm{II})$ to $\mathrm{Eu}(\mathrm{III})$ and produces singlet oxygen; meanwhile, the energy originating from dimers of singlet oxygen is accepted by the complex Eu(III)EDTA $^{-}$. The excited Eu(III) ions undergo radiative deactivation and emit the chemiluminescence.

\section{Acknowledgements}

This project was funded by the National Science Fund for Distinguished Young Scholars of China (No. 20125514), the Natural Science Foundation of China (Nos 20437020 and 50273046) and a Major Research Program of the Chinese Academy of Sciences (No. KZCX3-SW-432). 


\section{REFERENCES}

1. Agbaria RA, Oldham PB, McCarroll M, McGown LB, Warner IM. Molecular fluorescence, phosphorescence, and chemiluminescence spectrometry. Anal. Chem. 2002; 74: 3952-3962.

2. Hindson BJ, Barnett NW. Analytical application of acidic potassium permanganate as a chemiluminescence reagent. Anal. Chim. Acta 2001; 445: 1-19.

3. Richardson DE, Yao HR, Frank KM, Bennett DA. Equilibria, kinetics, and mechanism in the bicarbonate activation of hydrogen peroxide: oxidation of sulphides by peroxymonocarbonate. J. Am. Chem. Soc. 2000; 122: 1729-1739.

4. Swern D. In Organic Peroxides. Wiley: New York, 1970: 313-516.

5. Lin JM, Yamada M. Chemiluminescent reaction of fluorescent organic compounds with $\mathrm{KHSO}_{5}$ using cobalt (II) as catalyst and its first application to molecular imprinting. Anal. Chem. 2000; 72: $1148-1155$.

6. Steele WV, Appelmen EH. The standard enthalpy of formation of peroxymonosulphate $\left(\mathrm{HSO}_{5}{ }^{-}\right)$and the standard electrode potential of the peroxymonosulphate-bisulphate couple. J. Chem. Thermodyn. 1982; 14: 337-344.

7. Richardson DE, Regino CAS, Yao HR, Johnson JV. Methionine oxidation by peroxymonocarbonate, a reactive oxygen species formed from $\mathrm{CO}_{2}$ /bicarbonate and hydrogen peroxide. Free Radic. Biol. Med. 2003; 35: 1538-1550.

8. Yao HR, Richardson DE. Epoxidation of alkenes with bicarbonateactivated hydrogen peroxide. J. Am. Chem. Soc. 2000; 122: 32203221.

9. Bennett DA, Yao HR, Richardson DE. Mechanism of sulphide oxidations by peroxymonocarbonate. Inorg. Chem. 2001; 40: 29963001 .

10. Lane BS, Vogt M, DeRose VJ, Burgess K. Manganese-catalyzed epoxidations of alkenes in bicarbonate solutions. J. Am. Chem. Soc. 2002; 124: 11946-11954.

11. Yao HR, Richardson DE. Bicarbonate surfoxidants: micellar oxidations of aryl sulphides with bicarbonate-activated hydrogen peroxide. J. Am. Chem. Soc. 2003; 125: 6211-6221.

12. Flanagan J, Jones DP, Griffith WP, Skapski AC, West AP. On the existence of peroxocarbonates in aqueous solution. J. Chem. Soc. Chem. Commun. 1986; 20-21.

13. Drago RS, Frank KM, Yang YC, Wagner GW. In Proceedings of the 1997 ERDEC Scientific Conference on Chemical and Biological Defense Research, US Army Edgewood Research, Development, and Engineering Center, 1998.

14. McCoy HN. The separation of europium from other rare earths. J. Am. Chem. Soc. 1935; 57: 1756-1756.

15. Sabbatini N, Guardigli M, Lehn GM. Luminescent lanthanide complexes as photochemical supramolecular devices. Coord. Chem. Rev. 1993; 123: 201-228.

16. de Sá GF, Malta OL, de Mello Donegá C, Simas AM, Longo RL, Santa-Cruz PA, da Silva Jr. EF. Spectroscopic properties and design of highly luminescent lanthanide coordination complexes. Coord. Chem. Rev. 2000; 196: 165-195.

17. Vicentini G, Zinner LB, Zukerman-Schpector J, Zinner K. Luminescence and structure of europium compounds. Coord. Chem. Rev. 2000; 196: 353-382.
18. McClure DS, Kiss ZJ. Survey of the spectra of the divalent rareearth ions in cubic crystals. J. Chem. Phys. 1963; 39: 3251-3257.

19. Class RC, Faulkner IR. Electrogenerated chemiluminescence from the tris(2,2'-bipyridine)ruthenium(II) system. An example of S-route behavior. J. Phys. Chem. 1981; 85: 1160-1165.

20. Elbanowski M, Staninski K, Kaczmarek M, Lis S. Energy transfer in the chemiluminescent system: $\mathrm{Eu}(\mathrm{II}) /(\mathrm{III})-\mathrm{N}_{3}{ }^{-}-\mathrm{H}_{2} \mathrm{O}_{2} . J$. Alloys Comp. 2001; 323-324: 670-672.

21. Nakano M, Sugioka K, Ushijma Y, Goto T. Chemiluminescence probe with Cypridina luciferin analog, 2-methyl-6-phenyl-3,7dihydroimidazo [1,2- $a$ ] pyrazin-3-one, for estimating the ability of human granulocytes to generate $\mathrm{O}_{2}^{-}$. Anal. Biochem. 1986; 159: $363-369$.

22. Hosaka S, Itagaki T, Kuramitsu Y. Selectivity and sensitivity in the measurement of reactive oxygen species (ROS) using chemiluminescent microspheres prepared by the binding of acridinium ester or ABEI to polymer microspheres. Luminescence 1999; 14: 349-354.

23. Li HR, Wu LZ, Tung CH. Reactions of singlet oxygen with olefins and sterically hindered amine in mixed surfactant vesicles. J. Am. Chem. Soc. 2000; 122: 2446-2451.

24. Yamakoshi Y, Umezawa N, Ryu A, Arakane K, Miyata N, Goda Y, Masumizu T, Nagano T. Active oxygen species generated from photo-excited fullerene $\left(\mathrm{C}_{60}\right)$ as potential medicines: $\mathrm{O}_{2}{ }^{-}$ versus ${ }^{1} \mathrm{O}_{2}$. J. Am. Chem. Soc. 2003; 125: 12803-12809.

25. Turro NJ, Chow MF, Rigaudy J. Mechanism of thermolysis of endoperoxides of aromatic compounds. Activation parameters, magnetic field, and magnetic isotope effects. J. Am. Chem. Soc. 1981; 103: 7218-7224.

26. Aubry JM, Cazin B. Chemical sources of singlet oxygen. 2. Quantitative generation of singlet oxygen from hydrogen peroxide disproportionation catalyzed by molybdate ions. Inorg. Chem. 1988; 27: 2013-2014.

27. Ahsan UK, Michael K. Chemiluminescence arising from simultaneous transitions in pairs of singlet oxygen molecules. J. Am. Chem. Soc. 1970; 92: 3293-3300.

28. Ross AB, Mallard WG, Helman WP, Buxton JV, Huie RE, Neta P. NIST Standard References Database 40, Version 2.01994.

29. Bielski BHJ, Cabelli DE, Arudi RL, Ross AB. Reactivity of $\mathrm{HO}_{2} /$ $\mathrm{O}_{2}^{-}$radicals in aqueous solution. J. Phys. Chem. Ref. Data 1985; 14: $1041-1100$.

30. Brittain HG, Choppin GR, Barthelemy PP. pH dependence of the metal ion hydration state in lanthanide complexes of polyaminopolycarboxylate ligands. J. Coord. Chem. 1992; 26: 143-153.

31. Elbanowski M, Lis S, Makowska B, Konarski J. Fluorescence of lanthanide(III) complexes in aqueous solutions: the influence of $p H$ and solution composition. Monatsh Chem. 1985; 116: 901911.

32. Elbanowski M, Kacznarek M, Staninski K. The influence of aminopolycarboxylic acids on the chemiluminescence of the $\mathrm{Eu}(\mathrm{II}) / \mathrm{Eu}(\mathrm{III})-\mathrm{H}_{2} \mathrm{O}_{2}$ system. J. Alloys Comp. 1998; 275-277: 225 229.

33. Lloyd RA. Low level chemiluminescence from hydrocarbon autooxidation reactions. Trans Faraday Soc. 1965; 61: 2182-2193.

34. Hayashi J, Yamada M, Hobo T. Schiff base chemiluminescence with Fenton's reagent for the determination of primary amines and amino acids. Anal. Chim. Acta 1991; 247: 27-35. 